\title{
Nontypeable Haemophilus influenzae in chronic obstructive pulmonary disease and lung cancer
}

This article was published in the following Dove Press journal:

International Journal of Chronic Obstructive Pulmonary Disease

26 January 2011

Number of times this article has been viewed

\author{
Seyed Javad Moghaddam' \\ Cesar E Ochoa ${ }^{1,2}$ \\ Sanjay Sethi ${ }^{3}$ \\ Burton F Dickey ${ }^{1,4}$ \\ 'Department of Pulmonary Medicine, \\ the University of Texas MD Anderson \\ Cancer Center, Houston, TX, USA; \\ ${ }^{2}$ Tecnológico de Monterrey School \\ of Medicine, Monterrey, Nuevo \\ León, Mexico; ${ }^{3}$ Department of \\ Medicine, University at Buffalo, State \\ University of New York, Buffalo, NY, \\ USA $;{ }^{4}$ Center for Inflammation and \\ Infection, Institute of Biosciences and \\ Technology, Texas A\&M Health Science \\ Center, Houston, TX, USA
}

\begin{abstract}
Chronic obstructive pulmonary disease (COPD) is predicted to become the third leading cause of death in the world by 2020. It is characterized by airflow limitation that is not fully reversible. The airflow limitation is usually progressive and associated with an abnormal inflammatory response of the lungs to noxious particles and gases, most commonly cigarette smoke. Among smokers with COPD, even following withdrawal of cigarette smoke, inflammation persists and lung function continues to deteriorate. One possible explanation is that bacterial colonization of smoke-damaged airways, most commonly with nontypeable Haemophilus influenzae (NTHi), perpetuates airway injury and inflammation. Furthermore, COPD has also been identified as an independent risk factor for lung cancer irrespective of concomitant cigarette smoke exposure. In this article, we review the role of NTHi in airway inflammation that may lead to COPD progression and lung cancer promotion.
\end{abstract}

Keywords: COPD, NTHi, inflammation

\section{Introduction}

The pooled global prevalence of chronic obstructive pulmonary disease (COPD) in adults aged 40 years or older is $\sim 10 \%$, and it is a leading cause of morbidity and mortality in the US. ${ }^{1-5}$ COPD is believed to be caused by inflammation induced by inhaled smoke and particulates, and possibly by infecting pathogens as well, leading to the structural changes in airways and alveoli that result in irreversible airflow limitation (Figure 1). Despite the fact that smoking causes most cases of COPD, only $25 \%$ of smokers develop COPD. ${ }^{6,7}$ Conversely, epidemiologic data indicate that approximately 1 of 6 patients with COPD has never smoked. ${ }^{8}$ This variable susceptibility to COPD most likely reflects genetic variations in the inflammatory and structural responses to inhaled smoke and to microorganisms colonizing the airways of smokers. ${ }^{9-11}$ The most common colonizing bacterium is nontypeable (ie, unencapsulated) Haemophilus influenzae (NTHi). ${ }^{12,13}$ This organism is found in the lower respiratory tract of $\sim 30 \%$ of individuals with COPD at any time. ${ }^{12,14-17}$ In addition to colonization during clinically stable periods, acquisition of new strains of NTHi is an important cause of lower respiratory tract infection, resulting in exacerbations of COPD. ${ }^{13,18-20}$ Together, these findings suggest that persistent or repetitive exposure of the airway to NTHi products may contribute to airway inflammation in COPD. ${ }^{18}$ Furthermore, several studies have found that smokers with COPD have an increased risk of lung cancer (3- to 10-fold) compared with smokers with comparable cigarette exposure but without COPD. ${ }^{21,22}$ In this review, we will discuss the existing data regarding the roles that NTHi plays in COPD development and lung cancer promotion.
Correspondence: Seyed Javad Moghaddam Department of Pulmonary Medicine, The University of Texas MD Anderson Cancer Center, 2I I I W Holcombe Boulevard, Suite 703F, Houston, TX 77030, USA Tel + I 7I35630423

Fax + I 71356304 II

Email smoghadd@mdanderson.org submit your manuscript | www.dovepress.com

Dovepress

DOI: $10.2147 /$ COPD.SI5417 


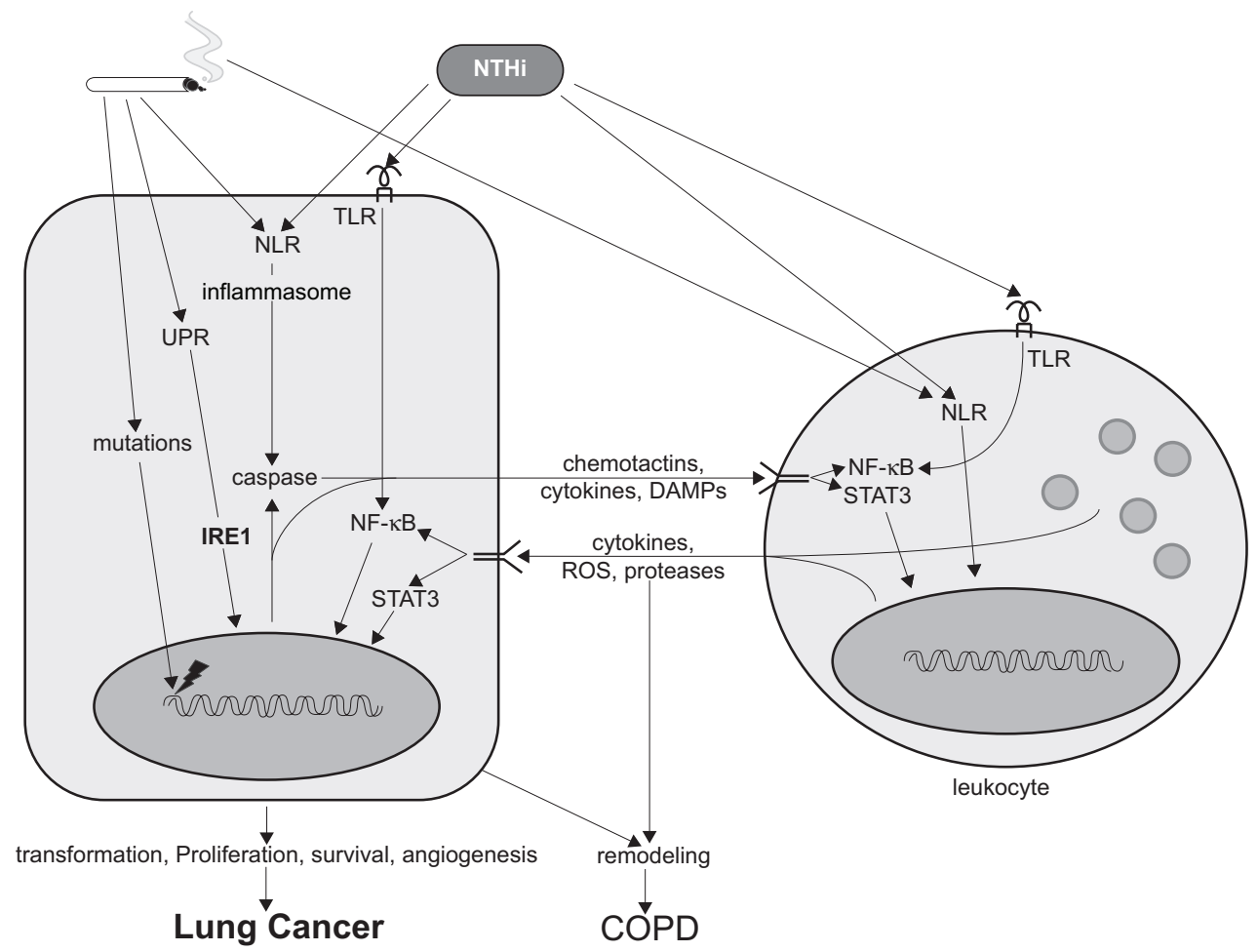

Figure I Effects of cigarette smoke and NTHi in the pathogenesis of lung cancer and COPD. Two inputs (cigarette smoke and microbial infection, top) act on two broad cell types (epithelial, left, and leukocyte, right) within the lungs to induce two outputs (lung cancer and COPD, bottom) as follows. Hydrocarbons and ROS in cigarette smoke induce mutations in epithelial cells that initiate carcinogenesis. Hydrocarbons, ROS, and particles in smoke activate the UPR and NLRs in epithelial cells and resident leukocytes, such as macrophages, inducing inflammation through key mediators such as IREI, the inflammasome, and NF- $\kappa$ B. Microbial infection of smoke-damaged airways, particularly with NTHi, results in further inflammation by activating pattern recognition receptors such as the NLRs and TLRs. Activated epithelial cells amplify inflammation by signaling through chemotactins, cytokines, and DAMPs to resident and recruited leukocytes (CD8 ${ }^{+} \mathrm{T}$ cells, CD4+ ThI7 cells, and B cells). In turn, activated leukocytes signal to epithelial cells through NF- $\mathrm{KB}$ and STAT3 to further amplify inflammation and generate proliferative and survival signals that promote carcinogenesis. COPD results from phenotypic changes in epithelial cells, such as mucous metaplasia or cell death, along with other structural changes such as proliferation or death of mesenchymal cells and deposition or destruction of extracellular matrix that together are termed remodeling.

Abbreviations: COPD, chronic obstructive pulmonary disease; DAMPs, damage-associated molecular patterns; IREI, inositol-requiring enzyme I; NF-KB, nuclear transcription factor-KB; NLRs, Nod-like receptors; NTHi, nontypeable Haemophilus influenzae; ROS, reactive oxygen species; STAT3, signal transducer and activator of transcription 3; TLRs, Toll-like receptors; UPR, unfolded protein response.

\section{Inflammation in COPD}

Based on the definition of the Global Initiative for Chronic Obstructive Lung Disease, COPD is "a disease state characterized by airflow limitation that is not fully reversible. The airflow limitation is usually progressive and associated with an abnormal inflammatory response of the lungs to noxious particles and gases". ${ }^{23}$ Although COPD and asthma both involve inflammation in the respiratory tract, the inflammatory processes differ markedly. ${ }^{10,24}$ Histopathological studies show a predominant involvement of peripheral airways (bronchioles) and lung parenchyma in COPD, whereas asthma involves inflammation in all airways but minimal involvement of the lung parenchyma. ${ }^{25}$ Both innate and adaptive immune responses are involved in lung inflammation in patients with COPD.

\section{Inflammatory cells}

In histopathologic specimens of distal lung and in bronchoalveolar lavage fluid (BALF) from COPD patients, macrophages and neutrophils are prominent. ${ }^{26-28}$ There is also an increase in the total numbers of $\mathrm{T}$ lymphocytes in lung parenchyma and peripheral and central airways of patients with COPD, with a greater increase in $\mathrm{CD} 8^{+}$than in $\mathrm{CD} 4^{+}$ cells. ${ }^{25,29,30}$ Although the absolute number of $\mathrm{CD} 8^{+}$cells is more than $\mathrm{CD}^{+}$cells, there is strong evidence to support a role for $\mathrm{CD}^{+} \mathrm{T}$ helper 1 (Th1) cells in maintenance of chronic inflammation in COPD. ${ }^{31,32}$ Loss of lung function in patients with COPD is associated with a high percentage of $\mathrm{CD} 4^{+}$ and $\mathrm{CD} 8^{+} \mathrm{T}$ lymphocytes that express chemokine receptors CCR5 and CXCR3 (markers of Th1 cells), but not CCR3 or CCR4 (markers of Th2 cells). ${ }^{33,34} \mathrm{CD} 8^{+}$cells are typically increased in airway infections, and it is possible that chronic or recurrent colonization of the lower respiratory tract of COPD patients by bacterial and viral pathogens contributes to this inflammatory response. ${ }^{35}$ It has also been shown that $\mathrm{CD} 8^{+} \mathrm{T}$ cells are required for inflammation and destruction in cigarette smoke-induced emphysema in mice. ${ }^{36}$ 
The accumulated volume of B cells in small airways (mainly seen in lymphoid aggregates) ${ }^{2}$ and in bronchial biopsies of large airways ${ }^{37}$ is higher in patients with COPD than in controls without airflow limitation and even higher in more severe COPD. The humoral, or antibody, immune response is essential for host defense against viral and bacterial pathogens. B cells probably contribute to the inflammatory process and/or the development and perpetuation of COPD by means of a specific antigen-driven process. ${ }^{38}$ The lung has the ability to respond quickly to some pathogens through stimulation of resident antigen-specific memory B cells. Alternatively, after exposure to a new pathogen, the lung can generate de novo both a systemic and local (mucosal) antibody response. The resulting production of antigen-specific IgG and IgA acts in concert to help clear the invading pathogen and reduce subsequent colonization of respiratory epithelium. ${ }^{39}$ Primary adaptive responses are triggered by immature myeloid dendritic cells (DCs), which carry antigen from the lungs to regional lymph nodes. ${ }^{40}$ Antigen presentation by these mature DCs is required to activate naive $\mathrm{CD}^{+} \mathrm{T}$ cells, which are essential to generate polarized type 1 or type 2 responses and for robust immunologic memory. Persistent and chronic inflammation recruits natural killer (NK) cells and more DCs. ${ }^{40} \mathrm{NK}$ cells exposed to interleukin-12 (IL-12) favor survival of DCs that prime for Th1 responses, whereas NK cells exposed to IL-4 do not exert DC selection, leading to Th2 responses. Additionally, previous pulmonary infections or immune responses increase the number of lung DCs and populate the lungs with clones of memory $\mathrm{B}$ cells and $\mathrm{T}$ cells that are immediately available to respond to infections. ${ }^{40}$

In addition to the traditional Th1 and Th2 subtypes, recent developments in cytokine biology imply that COPD might be better explained by the T helper 17 (Th17) phenotype. ${ }^{41}$ Effector molecules produced by $\mathrm{CD}^{+} \mathrm{Th} 17$ cells include IL-17A, IL-17F, and IL-22. ${ }^{41}$ IL-17A and IL-17F both bind to the IL-17 receptor (IL-17R) ${ }^{42}$ It has been shown that IL-17R signaling is required for lung $\mathrm{CXC}$ chemokine and granulocyte colony-stimulating factor (G-CSF) expression, neutrophil recruitment, and host defense against Gram-negative bacteria. ${ }^{43} \mathrm{IL}-17 \mathrm{~A}$, the prototype of this new cytokine family, is a $20-30-\mathrm{kDa}$ glycosylated homodimeric cytokine produced predominantly by $\mathrm{T}$ cells. ${ }^{44}$ Many of the inflammatory effects of Th17 cells are attributed to the expression of IL-17A. For example, IL-17A upregulates the expression of a number of CXCR2 chemokines, including CXCL1, CXCL6, and CXCL8, together with the neutrophil survival factors granulocyte-macrophage colony-stimulating factor (GM-CSF) and G-CSF from the airway epithelium. This would suggest that Th17 cells are important in promoting and sustaining the neutrophilic inflammation observed in COPD. In addition, IL-17A can act synergistically with viral infection as well as other inflammatory mediators that include tumor necrosis factor (TNF) to potentiate these responses. ${ }^{45,46}$ Transgenic overexpression of IL-17A in the lung induces inflammation and mucous metaplasia. ${ }^{47}$ Primary human tracheobronchial epithelial cells stimulated by an extensive panel of cytokines upregulated the MUC5AC and MUC5B genes in response to IL-17A. ${ }^{48}$ Additionally, IL-17A potently induces epithelial cells and fibroblasts to secrete neutrophil attractants, notably CXCL8 ${ }^{48-51}$ Finally, IL-17 family members increase the sensitivity of macrophages to pathogen-associated molecular patterns and may even directly induce TNF. ${ }^{51}$

\section{Inflammatory mediators and signaling pathways}

Cellular inflammation in COPD is accompanied by increased levels of proinflammatory cytokines, which amplify inflammation via the activation of the NF- $\mathrm{KB}$ pathway, leading to increased expression of multiple inflammatory genes. ${ }^{52-56}$ NF- $\kappa B$ activation occurs primarily through I $\kappa B$ kinase (IKK)-dependent phosphorylation and subsequent degradation of specific inhibitors, the IKBs, which retain NF- $\kappa B$ in the cytoplasm. Upon activation, NF- $\kappa B$ dimers enter the nucleus, where they modulate transcription of a large variety of target genes. ${ }^{52,53,57,58}$ These genes code for mediators of immune and inflammatory reactions, such as TNF, IL-1 $\beta$, IL- 6 , IFN- $\gamma$, IL-18, IL-32, and Th17 cytokines, the chemokine IL-8, and cell adhesion molecules.

TNF is mostly produced by macrophages, and also by many other cells, such as mast cells, epithelial cells, and B and $\mathrm{T}$ cells, and activates NF- $\mathrm{\kappa B} .{ }^{59} \mathrm{TNF}$ levels are increased in the sputum of patients with COPD during exacerbations ${ }^{60}$ and contribute importantly to cigarette smoke-induced emphysema in mice. ${ }^{59}$

IL-1 $\beta$ stimulates alveolar macrophages from patients with COPD to secrete inflammatory factors, ${ }^{61}$ and together with TNF induces ICAM-1 expression on endothelial cells. ${ }^{54}$ IL-18, part of the IL-1 superfamily, plays an important role in Th1 polarization and various Th1-type diseases, inducing TNF, IL-1 $\beta$, GM-CSF, and chemokine production by monocytes and $\mathrm{T}$ lymphocytes. ${ }^{62}$ In mouse models, it has been shown that constitutive IL-18 overproduction in the lungs induces emphysema. ${ }^{63}$

IL-6 is acutely produced by monocytes and macrophages at the site of inflammation, as well as by $\mathrm{T}$ cells in chronic 
inflammation. IL-6 activates intracellular signaling of signal transducer and activator of transcription 3 (STAT3) in epithelial and immune cells. ${ }^{64}$ STAT3 upregulation was observed in lung tissue from both smokers and nonsmokers with COPD, and this was associated with upregulation of its target genes. ${ }^{65}$ Increased levels of IL-6 have been found in induced sputum, exhaled breath condensate, and BALF from COPD patients, ${ }^{66}$ and when overexpressed in the mouse airways results in emphysema-like airspace enlargement and airway inflammation. ${ }^{67}$

IFN- $\gamma$ is produced by Th1 cells, activated macrophages, and DCs, inducing them to produce IL-12, the main Th1inducing cytokine. When overexpressed in the murine lung it results in emphysema, and it has also been shown to be upregulated in lymphocytes isolated from emphysematous lung tissue samples, BALF, and sputum from COPD patients..$^{33,68,69}$

IL-32 produced in NK cells, T cells, epithelial cells, and monocytes has been recently recognized as a proinflammatory cytokine..$^{70}$ An increased expression of IL-32 in the lung tissue of patients with COPD has been demonstrated and correlates with the level of TNF and the degree of airway obstruction, suggesting that IL-32 is involved in the specific immune response observed in COPD and may have an impact on disease progression. ${ }^{71,72}$

IL-8, a CXC chemokine, is a neutrophil chemoattractant and activator. It is secreted by macrophages, neutrophils, and airway epithelial cells and may contribute to COPD progression by attracting neutrophils to the lung. ${ }^{73}$ Increased levels found in sputum samples from COPD patients correlate with the airway bacterial load, and its constitutive overexpression in the lungs of mice induces emphysema, furthermore suggesting its important role in the pathogenesis of COPD. ${ }^{53,63}$

\section{NTHi and immune responses}

NTHi is a small $(1.0 \times 0.3 \mu \mathrm{m})$ Gram-negative coccobacillus that lacks a polysaccharide capsule (hence its nontypeable classification). It colonizes the upper respiratory tract of up to $75 \%$ of normal adults and primarily acts as a mucosal pathogen. ${ }^{74}$ Although it lacks a mucinous capsule, NTHi possesses characteristic coat proteins.

The P2 protein is the major outer membrane protein (OMP) of NTHi, constituting $\sim 50 \%$ of the protein content of the outer membrane. P2 is a target of human serum bactericidal antibody, indicating that the protein is important in the human immune response to $\mathrm{NTHi}^{75} \mathrm{P} 6$ is a $16-\mathrm{kDa}$ peptidoglycan-associated lipoprotein that is present in the outer membrane of all strains of $\mathrm{NTHi}^{76}$ and shows a high degree of sequence conservation among strains. ${ }^{77}$ Several lines of evidence suggest that P6 elicits bactericidal antibody responses. ${ }^{76,78}$ Berenson et al have shown that P6 is a specific trigger of bacteria-induced human macrophage inflammatory events, with IL-8 and TNF as key effectors of P6-induced macrophage responses. ${ }^{79}$ Another study has shown that although the migration of mature DCs into the pulmonary lymph nodes is attenuated after repeated airway challenge of mice with OMPs of NTHi, the in vitro P6-specific T cell proliferation in cultured pulmonary lymph node cells was enhanced and subsequently linked to the development of P6-specific IgA production and the development of protective immunity in the airway of mice. ${ }^{80}$

NTHi lipooligosaccharide (LOS) is a major virulence determinant and may play a role in colonization and invasion of mucosal surfaces in the respiratory tract. ${ }^{81} \mathrm{NTHi}$ LOS is analogous to the lipopolysaccharide (LPS) of enteric Gram-negative bacteria in that it contains lipid A linked by 3-deoxy-D-manno-octulosonic acid to a heterogeneous sugar polymer. ${ }^{82,83}$ NTHi LOS, however, differs from classic enterobacterial LPS in that it does not contain repeating $\mathrm{O}$-antigen units and is therefore more similar to that derived from Neisseria and Bordetella species. ${ }^{82,83}$

Like most other bacterial infections, NTHi infections induce inflammation with prominent release of cytokines and chemokines. Extensive in vitro studies have shown that NTHi lysate activates the NF- $\kappa$ B pathway in airway epithelial cells and markedly increases expression and release of proinflammatory mediators, including IL-6, IL-8, and TNF. ${ }^{18,84-86}$ Airway epithelial cells are capable of sensing and responding to inflammatory stimuli through innate immune mechanisms that result in lung inflammation. ${ }^{87}$ These mechanisms mostly function through Toll-like receptors (TLRs), a family of evolutionarily conserved transmembrane receptors that serve as pattern recognition receptors. They recognize conserved microbial motifs in molecules such as bacterial LPS, peptidoglycan, flagellin, unmethylated $\mathrm{CpG}$ DNA, and doubleand single-stranded RNA. Activation of the corresponding TLR by any of these molecules results in the activation of antimicrobial responses ${ }^{88}$ and the initiation of an inflammatory response, alerting the host to the presence of microbial invasion and initiating an immune response. ${ }^{89,90}$

Because the TLRs share sequence similarity with the IL-1 receptor (IL-1R) family in their cytoplasmic regions, it is not unexpected that downstream events are mediated by common components, such as myeloid differentiation primary response gene (88) (MyD88). MyD88 is an adaptor protein 
that links the IL-1R to IL-1R-associated protein kinase (IRAK), a serine-threonine kinase that is related to the pelle kinase of Drosophila. Upon binding of ligand to IL-1R, IRAK phosphorylates, subsequently dissociates from the receptor complex and associates with TNF-receptor-activated factor 6 (TRAF6). This process results in the activation of two different pathways that involve the c-Jun NH2-terminal kinase and p38 mitogen-activated protein kinase (MAPK) family and the Rel family transcription factor NF- $\kappa \mathrm{B} .{ }^{91,92}$

TLR-4 is the signaling receptor for LPS, the major proinflammatory component of the Gram-negative cell wall, in concert with CD14, which serves as the ligand-binding part of the LPS receptor complex. Triggering of TLR-4 results in the activation of two distinct intracellular pathways, one that relies on the common TLR adaptor MyD88 and one that is mediated by Toll/IL-1R domain-containing adaptorinducing IFN- $\beta$ (TRIF). ${ }^{93}$ Wieland et al have shown that alveolar macrophages from CD14 and TLR-4 knockout (KO) mice are virtually unresponsive to NTHi in vitro. ${ }^{93}$ Intranasal administration of NTHi in the mouse results in a brisk elaboration of IL-1 $\beta$, IL-6, TNF, macrophage-inflammatory protein (MIP)-1 $\alpha$, and MIP-2 in BALF and a corresponding mobilization of intrapulmonary neutrophils. After intranasal infection with NTHi, CD14 and TLR-4 KO mice showed an attenuated early inflammatory response in their lungs with diminished IL-1 $\beta$, IL-6, TNF, MIP- $1 \alpha$, and MIP-2 in BALF and a notable absence of intrapulmonary neutrophils, which was associated with a strongly reduced clearance of NTHi from the respiratory tract. ${ }^{93,94}$ Additionally, MyD88 KO, but not TRIF mutant mice, showed an increased bacterial load in their lungs upon infection with NTHi. ${ }^{93}$ These data demonstrate that the MyD88-dependent pathway of TLR-4 is important for an effective innate immune response to respiratory tract infection caused by NTHi. This suggests that the airway epithelia might contribute to sensing NTHi infection and signaling the innate immune response. ${ }^{94}$

TLR-2 also plays a critical role in mediating inflammatory responses against bacterial pathogens in the lung. ${ }^{95}$ NTHi strongly activates NF- $\mathrm{KB}$ in human epithelial cells via two distinct signaling pathways: NF- $\kappa$ B translocation-dependent and NF- $\kappa B$ translocation-independent pathways.$^{85}$ The NF- $\kappa B$ translocation-dependent pathway involves activation of the NF- $\kappa \mathrm{B}$-inducing kinase (NIK)-IKK $\alpha / \beta$ complex, leading to $\mathrm{I} \kappa \mathrm{B} \alpha$ phosphorylation and degradation, whereas the NF- $\mathrm{KB}$ translocation-independent pathway involves activation of MKK3/6-MAPK. TLR-2 is required for NTHi-induced NF- $\mathrm{BB}$ activation through both pathways, and OMP P6 appears to also activate NF- $\kappa \mathrm{B}$ via similar signaling pathways.$^{85} \mathrm{NTHi}$ also induces COX-2 and PGE2 expression in a p38 MAPK and NF- $\kappa$ B-dependent manner through TLR2 in lung epithelial cells in vitro and lung tissues in vivo. ${ }^{96}$

\section{NTHi in COPD}

NTHi is frequently present in the airways of adults with COPD. ${ }^{14-17}$ This Gram-negative bacterium is found in the lower respiratory tract of $\sim 30 \%$ of individuals with COPD at any time, and with serial sampling more than $60 \%$ of COPD patients show colonization. ${ }^{97}$ Several studies have shown higher inflammatory responses in the presence of NTHi colonization in stable COPD patients and smokers without COPD. ${ }^{98-100}$ For example, colonized smokers, with or without COPD, had more bronchial neutrophilia compared with noncolonized ones. ${ }^{15}$ Bacterial colonization has also been associated with increased frequency of exacerbations and an accelerated decline in lung function. ${ }^{97}$ Furthermore, the acquisition of new NTHi serotypes is associated with exacerbations of COPD. ${ }^{12,13,18-20}$ In one study, NTHi was found in the bronchial tissues of $87 \%$ of patients with exacerbations compared with $33 \%$ of stable COPD patients and $0 \%$ of healthy controls. ${ }^{14}$ The immune response that develops after an exacerbation seems to be strain specific and protects against recurrent exacerbation due to the homologous strain but leaves the patient susceptible to exacerbations caused by antigenically unrelated heterologous strains, and this likely represents a mechanism for recurrent infections. ${ }^{101}$

Studies using molecular techniques indicate that some patients with COPD are persistently colonized with NTHi even after antimicrobial therapy and despite a negative sputum culture. This suggests that bacteria may cause a greater proportion of exacerbations than is revealed by sputum culture alone. ${ }^{102-104}$ Defective immune responsiveness and impaired phagocytosis by alveolar macrophages might provide an immunologic basis for persistence of NTHi in the airways of adults with COPD. ${ }^{105}$ Cigarette smoke induces mucus dysfunction by several mechanisms ${ }^{106-110}$ and ultimately increases mucin production, reduces mucus hydration, and decreases mucus clearance, which might also contribute to airway colonization in COPD patients. ${ }^{111}$ Other possible mechanisms of colonization include airway epithelial cell invasion, ${ }^{20,103}$ antigenic alteration, ${ }^{12-114}$ and biofilm formation. ${ }^{115}$

NTHi could contribute to COPD progression by inducing neutrophilic influx into the airways, neutrophil necrosis with release of neutrophil elastase and other matrix metalloproteinases, and production of oxygen radicals. ${ }^{79,86}$ These mediators can overwhelm the antiproteinase barrier of 
the lung and damage airway and alveolar structures, thereby amplifying smoking-induced lung damage. ${ }^{116}$ We have shown that weekly exposure of mice to an aerosolized NTHi lysate induces lung inflammation with a profile of mediators and inflammatory cells similar to that observed in COPD patients. ${ }^{117}$ Repetitive exposure to NTHi lysate results in a 10 -fold increase in total inflammatory cell numbers in BALF, dominated by neutrophils ( $81 \%$ ) with fewer macrophages and lymphocytes. This was accompanied by marked increases in inflammatory cytokines (TNF and IL-6), Th1 cytokines (IFN- $\gamma$ and IL-12), and the neutrophil chemoattractant KC. Consistent with the rapid rise in the levels of inflammatory cytokines, NF- $\kappa \mathrm{B}$ was rapidly activated after each exposure. In the weeks following chronic activation of this innate immune response, a marked COPD-like inflammatory process ensues. Peribronchiolar and perivascular inflammatory cell infiltration and lymphoid aggregates (after 8 weeks), similar to those described in COPD patients, were seen. The chronic inflammatory response was characterized by infiltration of the airway wall by macrophages, $\mathrm{CD} 20^{+} \mathrm{B}$ cells, $\mathrm{CD} 8^{+} \mathrm{T}$ cells, $\mathrm{CD}^{+} \mathrm{T}$ cells, and neutrophils. Structural changes in the lung parenchyma were closely associated with the chronic inflammatory response. There was increased fibrous tissue around airways, similar to that described in COPD patients, after 25 weekly NTHi exposures, and this further increased after 50 weeks of exposure. ${ }^{117}$ Flow cytometric analysis of BALF and lung homogenates after eight NTHi exposures has also shown an increased number of IL-17-producing $\mathrm{CD}^{+} \mathrm{T}$ cells (Th17 cells), associated with high expression of IL-17 in inflamed lung tissue and in the BALF (unpublished data). Furthermore, exposure of mice genetically deficient in IL-17R to the NTHi lysate resulted in a lower level of neutrophilic influx into the BALF and less inflammatory cell infiltration in lung tissue, indicating a major role for Th17 cells in NTHi-induced COPD-like airway inflammation (unpublished data). As transgenic overexpression of TNF in the airway epithelium caused BALF neutrophilia and inflammatory cell infiltration around airways, but not fibrosis, ${ }^{117}$ this suggests that innate immune inflammation alone is insufficient to induce airway fibrosis.

Studies have shown that both human and mouse alveolar epithelial type II (AT II) cells express MHC II molecules and that AT II cells are capable of activating T cells in vitro. ${ }^{118-120}$ A recent study shows that naive $\mathrm{CD}^{+} \mathrm{T}$ cells are specifically activated against a lung-specific antigen by AT II cells independently of lymphoid tissue and DCs in vivo. ${ }^{121}$ These data offer the strongest evidence to date that the lung itself, independent of the classical antigen-presenting cells of the immune system, can present foreign and self-peptides and differentiate $\mathrm{CD}^{+} \mathrm{T}$ cells into regulatory $\mathrm{T}$ cell subsets. ${ }^{122}$ We also demonstrated that NTHi lysate could induce innate resistance in the lungs, resulting in broad protection against a wide range of pathogens, ${ }^{87}$ which occurs independent of alveolar macrophages and recruited neutrophils. This protection derives from stimulation of local innate immune mechanisms, and activated lung epithelium is the most likely cellular effector of this response. Furthermore, gene expression analysis of lungs from NTHi-exposed mice demonstrated NF- $\kappa \mathrm{B}$ signaling to be the most enriched process, followed closely by interferons, IL-6/STAT3, and TLR signaling, including MyD88, TLR-2, and TLR-4. ${ }^{123,124}$ To further dissect the importance of the NF- $\mathrm{BB}$ pathway in this phenomenon, we have targeted NF- $\kappa \mathrm{B}$ in the airway epithelium using a genetic strategy and have demonstrated a lower level of neutrophilic influx into BALF after a single NTHi exposure (unpublished data). Together, these findings suggest that exposure of the airway to NTHi products contributes to lung inflammation and airway fibrosis in COPD, which is mediated by innate immune activation of epithelial cells that signal to adaptive immune cells.

\section{NTHi, COPD, and lung cancer}

Worldwide, lung cancer is the leading cause of cancer mortality and is expected to account for $30 \%$ of all male and $26 \%$ of all female cancer deaths in 2009. ${ }^{125}$ Cigarette smoking causes $90 \%$ of all lung cancers and is believed to do so primarily by inducing DNA mutations. ${ }^{126}$ In addition, epidemiologic data indicate that chronic inflammation also plays a role in lung epithelial carcinogenesis. ${ }^{127}$ Genetic factors have also been shown to play a role in determining susceptibility to lung cancer. These genetic factors are believed to confer an inherent susceptibility (exaggerated or maladaptive response) to chronic inflammation from cigarette smoking. Consistent with many cancer models, this inflammatory stimulus in the lungs results in tissue remodeling, DNA damage, and impaired cell cycle control. ${ }^{128}$

Multiple studies have found that smokers with COPD have an increased risk of lung cancer compared with smokers without COPD. ${ }^{21,22,127,129,130}$ There is strong evidence that a patient's forced expiratory volume in the first second of expiration is an independent prognostic marker for developing lung cancer in both smokers and exsmokers, ${ }^{129,130}$ and the incidence of lung cancer seems to be higher for those with more severe airflow obstruction. The presence of mild emphysema, even without demonstrable airflow obstruction, confers a substantial risk of developing lung cancer. ${ }^{131}$ The 
likelihood of developing lung cancer within 10 years is three-fold greater in patients with mild-to-moderate COPD and 10 -fold greater in patients with severe COPD compared with smokers with normal lung function. ${ }^{22}$ It has also been shown that increased lung cancer mortality is associated with a history of COPD, even among people who have never been active smokers. ${ }^{132}$

Several possible mechanisms may link lung cancer to COPD, and both genetic and environmental factors may play a role. This link could be related to inflammation and the body's attempt to repair emphysematous airspaces. ${ }^{133}$ On the basis of existing in vitro studies showing that NTHi activates proliferative and antiapoptotic signaling pathways, ${ }^{84,85,134}$ colonization with this bacterium may also promote carcinogenesis by stimulating growth and inhibiting apoptosis. We have shown that NTHi-induced COPD-like airway inflammation promotes lung cancer in a Clara cell-targeted K-ras mutant mouse model (CC-LR) of lung cancer. ${ }^{135}$ In contrast, existing epidemiologic data do not suggest any definite association between allergic airway inflammation (including asthma) and lung cancer, and some even suggest a protective role. ${ }^{136-140}$ To test this, CC-LR mice were sensitized intraperitoneally to ovalbumin (OVA) and then repetitively challenged with an OVA aerosol weekly for 8 weeks. This resulted in eosinophilic lung inflammation associated with increased levels of Th2 cytokines and mucous metaplasia of airway epithelium, similar to what is seen in asthma patients. However, this type of allergic inflammation did not result in a significant difference in lung surface tumor number. ${ }^{124}$

IL-6 has been implicated in inflammatory responses in human COPD, ${ }^{6,26}$ and the IL- 6 pathway has been found to be one of the mechanisms linking inflammation to cancer. ${ }^{64}$ Therefore, to determine the causal role of cytokines that mediate COPD-like inflammation in lung carcinogenesis, we genetically ablated IL-6 in CC-LR mice. This not only inhibited intrinsic lung cancer development (1.7-fold) but also inhibited the promoting effect of extrinsic COPDlike airway inflammation (2.6-fold). ${ }^{124}$ Taken together, we found that there is a clear specificity for the nature of inflammation in lung cancer promotion (Th17 type), and IL-6 has an essential role in lung cancer promotion. We suggest that COPD-like airway inflammation induced by NTHi provides a tumor microenvironment that favors lung tumor promotion and progression. This occurs via release of inflammatory mediators (IL-6 and TNF) from innate immune cells (neutrophils and macrophages) secondary to activation of epithelial innate immune signaling pathways (MyD88/
$\mathrm{NF}-\kappa \mathrm{B})$. This in turn activates more intracellular signaling pathways (NF- $\kappa \mathrm{B}$ and STAT3) in the airway epithelium and immune cells, resulting in activation of prosurvival, antiapoptotic, and proangiogenic signals accompanied by skewing toward a protumoral adaptive immune response (Th17 response) (Figure 1).

\section{Conclusion}

It appears that surface components of NTHi induce lung inflammation by innate immune signaling mechanisms and that this progresses to airway fibrosis by recruitment of the host adaptive immune system. A straightforward strategy to reduce the incidence of COPD is the prevention of tobacco consumption. However, because of the persistent risk among former smokers, additional strategies that stop the progression to advanced COPD are highly attractive. Based on the demonstrated ability of NTHi to induce lung inflammation and airway fibrosis and its persistent colonization of the airways of COPD patients, dissecting underlying mechanisms will help us to develop alternative preventive and therapeutic strategies in COPD patients. Furthermore, this would have a major impact on preventing the leading cause of cancer death by providing the basis for rationally directed therapy in patients at high risk for lung cancer development.

\section{Disclosure}

The authors report no conflicts of interest in this work.

\section{References}

1. Halbert RJ, Natoli JL, Gano A, Badamgarav E, Buist AS, Mannino DM. Global burden of COPD: systematic review and meta-analysis Eur Respir J. 2006;28(3):523-532.

2. Hogg JC, Chu F, Utokaparch S, et al. The nature of small-airway obstruction in chronic obstructive pulmonary disease. $N$ Engl J Med. 2004; 350(26):2645-2653.

3. Barnes PJ, Shapiro SD, Pauwels RA. Chronic obstructive pulmonary disease: molecular and cellular mechanisms. Eur Respir J. 2003 22(4):672-688.

4. Anderson GP, Bozinovski S. Acquired somatic mutations in the molecular pathogenesis of COPD. Trends Pharmacol Sci. 2003; 24(2):71-76.

5. Hogg JC. Chronic obstructive pulmonary disease: an overview of pathology and pathogenesis. Novartis Found Symp. 2001;234:4-19.

6. Barnes PJ. Chronic obstructive pulmonary disease. N Engl J Med. 2000; 343(4):269-280

7. Shapiro SD. End-stage chronic obstructive pulmonary disease: the cigarette is burned out but inflammation rages on. Am J Respir Crit Care Med. 2001;164(3):339-340.

8. Meyer PA, Mannino DM, Redd SC, Olson DR. Characteristics of adults dying with COPD. Chest. 2002;122(6):2003-2008.

9. Rennard SI. COPD: overview of definitions, epidemiology, and factors influencing its development. Chest. 1998;113(Suppl 4) 235S-241S

10. Saetta M, Turato G, Maestrelli P, Mapp CE, Fabbri LM. Cellular and structural bases of chronic obstructive pulmonary disease. Am J Respir Crit Care Med. 2001;163(6):1304-1309. 
11. Hnizdo E, Sullivan PA, Bang KM, Wagner G. Association between chronic obstructive pulmonary disease and employment by industry and occupation in the US population: a study of data from the Third National Health and Nutrition Examination Survey. Am J Epidemiol. 2002;156(8):738-746.

12. King PT, Hutchinson PE, Johnson PD, Holmes PW, Freezer NJ, Holdsworth SR. Adaptive immunity to nontypeable Haemophilus influenzae. Am J Respir Crit Care Med. 2003;167(4):587-592.

13. Murphy TF. Haemophilus influenzae in chronic bronchitis. Semin Respir Infect. 2000;15(1):41-51.

14. Bandi V, Apicella MA, Mason E, et al. Nontypeable Haemophilus influenzae in the lower respiratory tract of patients with chronic bronchitis. Am J Respir Crit Care Med. 2001;164(11):2114-2119.

15. Soler N, Ewig S, Torres A, Filella X, Gonzalez J, Zaubet A. Airway inflammation and bronchial microbial patterns in patients with stable chronic obstructive pulmonary disease. Eur Respir J. 1999;14(5): 1015-1022.

16. Monsó E, Ruiz J, Rosell A, et al. Bacterial infection in chronic obstructive pulmonary disease. A study of stable and exacerbated outpatients using the protected specimen brush. Am J Respir Crit Care Med. 1995; 152(4 Pt 1):1316-1320.

17. Zalacain R, Sobradillo V, Amilibia J, et al. Predisposing factors to bacterial colonization in chronic obstructive pulmonary disease. Eur Respir J. 1999;13(2):343-348.

18. Wilson R. Evidence of bacterial infection in acute exacerbations of chronic bronchitis. Semin Respir Infect. 2000;15(3):208-215.

19. van Schilfgaarde M, van Ulsen P, Eijk P, et al. Characterization of adherence of nontypeable Haemophilus influenzae to human epithelial cells. Infect Immun. 2000;68(8):4658-4665.

20. van Schilfgaarde M, Eijk P, Regelink A, et al. Haemophilus influenzae localized in epithelial cell layers is shielded from antibiotics and antibody-mediated bactericidal activity. Microb Pathog. 1999;26(5): 249-262.

21. Schottenfield D. The etiology and epidemiology of lung cancer. In: Pass HI, Mitchell JB, Johnson DH, Turrisi AT, Minna JD, editors. Lung Cancer: Principles and Practice. Philadelphia (PA): Lippincott, Williams \& Wilkins; 2000:367-388.

22. Mannino DM, Aguayo SM, Petty TL, Redd SC. Low lung function and incident lung cancer in the United States: data from the First National Health and Nutrition Examination Survey follow-up. Arch Intern Med. 2003;163(12):1475-1480.

23. Pauwels RA, Buist AS, Calverley PM, Jenkins CR, Hurd SS. Global strategy for the diagnosis, management, and prevention of chronic obstructive pulmonary disease. NHLBI/WHO Global Initiative for Chronic Obstructive Lung Disease (GOLD) Workshop summary. Am J Respir Crit Care Med. 2001;163(5):1256-1276.

24. Barnes PJ. Mechanisms in COPD: differences from asthma. Chest. 2000;117(Suppl 2):10S-14S.

25. Saetta M. Airway inflammation in chronic obstructive pulmonary disease. Am J Respir Crit Care Med. 1999;160(5 Pt 2):S17-S20.

26. Saetta M, di Stefano A, Turato G, et al. CD8+ T-lymphocytes in peripheral airways of smokers with chronic obstructive pulmonary disease. Am J Respir Crit Care Med. 1998;157(3 Pt 1):822-826.

27. Shapiro SD. The macrophage in chronic obstructive pulmonary disease. Am J Respir Crit Care Med. 1999;160(5 Pt 2):S29-S32.

28. Jeffery PK. Lymphocytes, chronic bronchitis and chronic obstructive pulmonary disease. Novartis Found Symp. 2001;234:149-161.

29. Finkelstein R, Fraser RS, Ghezzo H, Cosio MG. Alveolar inflammation and its relation to emphysema in smokers. Am J Respir Crit Care Med. 1995;152(5 Pt 1):1666-1672.

30. Majo J, Ghezzo H, Cosio MG. Lymphocyte population and apoptosis in the lungs of smokers and their relation to emphysema. Eur Respir J. 2001;17(5):946-953.

31. Vukmanovic-Stejic M, Vyas B, Gorak-Stolinska P, Noble A, Kemeny DM. Human Tc1 and Tc2/Tc0 CD8 T-cell clones display distinct cell surface and functional phenotypes. Blood. 2000;95(1): 231-240.
32. Saetta M, Mariani M, Panina-Bordignon P, et al. Increased expression of the chemokine receptor CXCR3 and its ligand CXCL10 in peripheral airways of smokers with chronic obstructive pulmonary disease. $\mathrm{Am} \mathrm{J}$ Respir Crit Care Med. 2002;165(10):1404-1409.

33. Grumelli S, Corry DB, Song LZ, et al. An immune basis for lung parenchymal destruction in chronic obstructive pulmonary disease and emphysema. PLoS Med. 2004;1(1):e8.

34. Lee SH, Goswami S, Grudo A, et al. Antielastin autoimmunity in tobacco smoking-induced emphysema. Nat Med. 2007;13(5):567-569.

35. Hill AT, Campbell EJ, Hill SL, Bayley DL, Stockley RA. Association between airway bacterial load and markers of airway inflammation in patients with stable chronic bronchitis. Am J Med. 2000; 109(4):288-295.

36. Maeno T, Houghton AM, Quintero PA, Grumelli S, Owen CA, Shapiro SD. CD8+ T cells are required for inflammation and destruction in cigarette smoke-induced emphysema in mice. J Immunol. 2007; 178(12):8090-8096.

37. Gosman MM, Willemse BW, Jansen DF, et al. Increased number of B-cells in bronchial biopsies in COPD. Eur Respir J. 2006;27(1): 60-64.

38. van der Strate BW, Postma DS, Brandsma CA, et al. Cigarette smokeinduced emphysema: a role for the B cell? Am J Respir Crit Care Med. 2006;173(7):751-758.

39. Twigg HL 3rd. Humoral immune defense (antibodies): recent advances. Proc Am Thorac Soc. 2005;2(5):417-421.

40. Curtis JL. Cell-mediated adaptive immune defense of the lungs. Proc Am Thorac Soc. 2005;2(5):412-416.

41. Ouyang W, Kolls JK, Zheng Y. The biological functions of $\mathrm{T}$ helper 17 cell effector cytokines in inflammation. Immunity. 2008; 28(4):454-467.

42. Aujla SJ, Dubin PJ, Kolls JK. Interleukin-17 in pulmonary host defense. Exp Lung Res. 2007;33(10):507-518.

43. Ye P, Rodriguez FH, Kanaly S, et al. Requirement of interleukin 17 receptor signaling for lung CXC chemokine and granulocyte colonystimulating factor expression, neutrophil recruitment, and host defense. J Exp Med. 2001;194(4):519-527.

44. Kolls JK, Linden A. Interleukin-17 family members and inflammation. Immunity. 2004;21(4):467-476.

45. Traves SL, Donnelly LE. Th17 cells in airway diseases. Curr Mol Med. 2008;8(5):416-426.

46. Laan M, Linden A. The IL-17 family of cytokines-applications in respiratory medicine and allergology. Recent Pat Inflamm Allergy Drug Discov. 2008;2(2):82-91.

47. Park H, Li Z, Yang XO, et al. A distinct lineage of CD4 T cells regulates tissue inflammation by producing interleukin 17. Nat Immunol. 2005; 6(11):1133-1141.

48. Molet S, Hamid Q, Davoine F, et al. IL-17 is increased in asthmatic airways and induces human bronchial fibroblasts to produce cytokines. J Allergy Clin Immunol. 2001;108(3):430-438.

49. Chen Y, Thai P, Zhao YH, Ho YS, DeSouza MM, Wu R. Stimulation of airway mucin gene expression by interleukin (IL)-17 through IL-6 paracrine/autocrine loop. J Biol Chem. 2003;278(19):17036-17043.

50. Vanaudenaerde BM, Wuyts WA, Dupont LJ, van Raemdonck DE, Demedts MM, Verleden GM. Interleukin-17 stimulates release of interleukin- 8 by human airway smooth muscle cells in vitro: a potential role for interleukin-17 and airway smooth muscle cells in bronchiolitis obliterans syndrome. J Heart Lung Transplant. 2003;22(11): 1280-1283.

51. Jones CE, Chan K. Interleukin-17 stimulates the expression of interleukin-8, growth-related oncogene-alpha, and granulocyte-colonystimulating factor by human airway epithelial cells. Am J Respir Cell Mol Biol. 2002;26(6):748-753.

52. Barnes PJ. The cytokine network in chronic obstructive pulmonary disease. Am J Respir Cell Mol Biol. 2009;41(6):631-638.

53. Górska K, Maskey-Warzechowska M, Krenke R. Airway inflammation in chronic obstructive pulmonary disease. Curr Opin Pulm Med. 2010; 16(2):89-96. 
54. Chung KF. Cytokines in chronic obstructive pulmonary disease. Eur Respir J Suppl. 2001;34:50s-59s.

55. Jeffery PK. Structural and inflammatory changes in COPD: a comparison with asthma. Thorax. 1998;53(2):129-136.

56. Barnes PJ. Mediators of chronic obstructive pulmonary disease. Pharmacol Rev. 2004;56(4):515-548.

57. Luo JL, Maeda S, Hsu LC, Yagita H, Karin M. Inhibition of NF-kappaB in cancer cells converts inflammation-induced tumor growth mediated by TNFalpha to TRAIL-mediated tumor regression. Cancer Cell. 2004; 6(3):297-305.

58. Pikarsky E, Porat RM, Stein I, et al. NF-kappaB functions as a tumour promoter in inflammation-associated cancer. Nature. 2004;431(7007):461-466.

59. Churg A, Wang RD, Tai H, Wang X, Xie C, Wright JL. Tumor necrosis factor-alpha drives $70 \%$ of cigarette smoke-induced emphysema in the mouse. Am J Respir Crit Care Med. 2004;170(5):492-498.

60. Aaron SD, Angel JB, Lunau M, et al. Granulocyte inflammatory markers and airway infection during acute exacerbation of chronic obstructive pulmonary disease. Am J Respir Crit Care Med. 2001; 163(2):349-355.

61. Culpitt SV, Rogers DF, Shah P, et al. Impaired inhibition by dexamethasone of cytokine release by alveolar macrophages from patients with chronic obstructive pulmonary disease. Am J Respir Crit Care Med. 2003;167(1):24-31.

62. Rovina N, Dima E, Gerassimou C, Kollintza A, Gratziou C, Roussos C. Interleukin-18 in induced sputum: association with lung function in chronic obstructive pulmonary disease. Respir Med. 2009; 103(7): 1056-1062.

63. Hoshino T, Kato S, Oka N, et al. Pulmonary inflammation and emphysema: role of the cytokines IL-18 and IL-13. Am J Respir Crit Care Med. 2007;176(1):49-62.

64. Naugler WE, Karin M. The wolf in sheep's clothing: the role of interleukin-6 in immunity, inflammation and cancer. Trends Mol Med 2008;14(3):109-119.

65. Qu P, Roberts J, LiY, et al. Stat3 downstream genes serve as biomarkers in human lung carcinomas and chronic obstructive pulmonary disease. Lung Cancer. 2009;63(3):341-347.

66. Bhowmik A, Seemungal TA, Sapsford RJ, Wedzicha JA. Relation of sputum inflammatory markers to symptoms and lung function changes in COPD exacerbations. Thorax. 2000;55(2):114-120.

67. Kuhn C 3rd, Homer RJ, Zhu Z, et al. Airway hyperresponsiveness and airway obstruction in transgenic mice. Morphologic correlates in mice overexpressing interleukin (IL)-11 and IL-6 in the lung. Am J Respir Cell Mol Biol. 2000;22(3):289-295.

68. Wang Z, Zheng T, Zhu Z, et al. Interferon gamma induction of pulmonary emphysema in the adult murine lung. $J$ Exp Med. 2000; 192(11):1587-1600.

69. Hodge G, Nairn J, Holmes M, Reynolds PN, Hodge S. Increased intracellular $\mathrm{T}$ helper 1 proinflammatory cytokine production in peripheral blood, bronchoalveolar lavage and intraepithelial $\mathrm{T}$ cells of COPD subjects. Clin Exp Immunol. 2007;150(1):22-29.

70. Kim SH, Han SY, Azam T, Yoon DY, Dinarello CA. Interleukin-32: a cytokine and inducer of TNFalpha. Immunity. 2005;22(1):131-142.

71. Calabrese F, Baraldo S, Bazzan E, et al. IL-32, a novel proinflammatory cytokine in chronic obstructive pulmonary disease. Am J Respir Crit Care Med. 2008;178(9):894-901.

72. Kundu M, Basu J. IL-32: an emerging player in the immune response network against tuberculosis? PLoS Med. 2006;3(8):e274.

73. Pesci A, Balbi B, Majori M, et al. Inflammatory cells and mediators in bronchial lavage of patients with chronic obstructive pulmonary disease. Eur Respir J. 1998;12(2):380-386.

74. Murphy TF. Haemophilus infections. In: Kasper DL, Braunwald E, Fauci AS, Hauser SL, Longo DL, Jameson JL, editors. Harrison's Principles of Internal Medicine. New York: McGraw Hill; 2005:864-867.

75. Yi K, Murphy TF. Mapping of a strain-specific bactericidal epitope to the surface-exposed loop 5 on the $\mathrm{P} 2$ porin protein of non-typeable Haemophilus influenzae. Microb Pathog. 1994;17(4):277-282.
76. Murphy TF, Bartos LC, Campagnari AA, Nelson MB, Apicella MA. Antigenic characterization of the P6 protein of nontypable Haemophilus influenzae. Infect Immun. 1986;54(3):774-779.

77. Nelson MB, Apicella MA, Murphy TF, Vankeulen H, Spotila LD, Rekosh D. Cloning and sequencing of Haemophilus influenzae outer membrane protein P6. Infect Immun. 1988;56(1):128-134.

78. Badr WH, Loghmanee D, Karalus RJ, Murphy TF, Thanavala Y. Immunization of mice with P6 of nontypeable Haemophilus influenzae: kinetics of the antibody response and IgG subclasses. Vaccine. 1999; 18(1-2):29-37.

79. Berenson CS, Murphy TF, Wrona CT, Sethi S. Outer membrane protein P6 of nontypeable Haemophilus influenzae is a potent and selective inducer of human macrophage proinflammatory cytokines. Infect Immun. 2005;73(5):2728-2735.

80. Kurita S, Koyama J, Onizuka S, et al. Dynamics of dendritic cell migration and the subsequent induction of protective immunity in the lung after repeated airway challenges by nontypeable Haemophilus influenzae outer membrane protein. Vaccine. 2006;24(31-32):5896-5903.

81. DeMaria TF, Apicella MA, Nichols WA, Leake ER. Evaluation of the virulence of nontypeable Haemophilus influenzae lipooligosaccharide htrB and $\mathrm{rfaD}$ mutants in the chinchilla model of otitis media. Infect Immun. 1997;65(11):4431-4435.

82. Mandrell RE, McLaughlin R, Aba Kwaik Y, et al. Lipooligosaccharides (LOS) of some Haemophilus species mimic human glycosphingolipids, and some LOS are sialylated. Infect Immun. 1992;60(4):1322-1328.

83. Gibson BW, Melaugh W, Phillips NJ, Apicella MA, Campagnari AA, Griffiss JM. Investigation of the structural heterogeneity of lipooligosaccharides from pathogenic Haemophilus and Neisseria species and of R-type lipopolysaccharides from Salmonella typhimurium by electrospray mass spectrometry. $J$ Bacteriol. 1993;175(9):2702-2712.

84. Jono H, Shuto T, Xu H, et al. Transforming growth factor-beta-Smad signaling pathway cooperates with NF-kappa B to mediate nontypeable Haemophilus influenzae-induced MUC2 mucin transcription. $J$ Biol Chem. 2002;277(47):45547-45557.

85. Shuto T, Xu H, Wang B, et al. Activation of NF-kappa B by nontypeable Hemophilus influenzae is mediated by toll-like receptor 2-TAK1dependent NIK-IKK alpha/beta-I kappa B alpha and MKK3/6-p38 MAP kinase signaling pathways in epithelial cells. Proc Natl Acad Sci U S A. 2001;98(15):8774-8779.

86. Khair OA, Davies RJ, Devalia JL. Bacterial-induced release of inflammatory mediators by bronchial epithelial cells. Eur Respir J. 1996; 9(9):1913-1922.

87. Clement CG, Evans SE, Evans CM, et al. Stimulation of lung innate immunity protects against lethal pneumococcal pneumonia in mice. Am J Respir Crit Care Med. 2008;177(12):1322-1330.

88. Evans SE, Xu Y, Tuvim MJ, Dickey BF. Inducible innate resistance of lung epithelium to infection. Annu Rev Physiol. 2010;72:413-435.

89. Akira S, Takeda K, Kaisho T. Toll-like receptors: critical proteins linking innate and acquired immunity. Nat Immunol. 2001;2(8): 675-680.

90. Uematsu S, Akira S. Toll-like receptors and Type I interferons. J Biol Chem. 2007;282(21):15319-15323.

91. Muzio M, Ni J, Feng P, Dixit VM. IRAK (Pelle) family member IRAK-2 and MyD88 as proximal mediators of IL-1 signaling. Science. 1997;278(5343):1612-1615.

92. Medzhitov R, Preston-Hurlburt P, Kopp E, et al. MyD88 is an adaptor protein in the hToll/IL-1 receptor family signaling pathways. Mol Cell. 1998;2(2):253-258.

93. Wieland CW, Florquin S, Maris NA, et al. The MyD88-dependent, but not the MyD88-independent, pathway of TLR4 signaling is important in clearing nontypeable Haemophilus influenzae from the mouse lung. J Immunol. 2005;175(9):6042-6049.

94. Wang X, Moser C, Louboutin JP, et al. Toll-like receptor 4 mediates innate immune responses to Haemophilus influenzae infection in mouse lung. J Immunol. 2002;168(2):810-815.

95. Texereau J, Chiche JD, Taylor W, Choukroun G, Comba B, Mira JP. The importance of Toll-like receptor 2 polymorphisms in severe infections. Clin Infect Dis. 2005;41 Supp1 7:S408-S415. 
96. Xu F, Xu Z, Zhang R, et al. Nontypeable Haemophilus influenzae induces COX-2 and PGE2 expression in lung epithelial cells via activation of p38 MAPK and NF-kappa B. Respir Res. 2008;9:16.

97. Sethi S, Maloney J, Grove L, Wrona C, Berenson CS. Airway inflammation and bronchial bacterial colonization in chronic obstructive pulmonary disease. Am J Respir Crit Care Med. 2006;173(9):991-998.

98. Bresser P, Out TA, van Alphen L, Jansen HM, Lutter R. Airway inflammation in nonobstructive and obstructive chronic bronchitis with chronic Haemophilus influenzae airway infection. Comparison with noninfected patients with chronic obstructive pulmonary disease. Am J Respir Crit Care Med. 2000;162(3 Pt 1):947-952.

99. White AJ, Gompertz S, Bayley DL, et al. Resolution of bronchial inflammation is related to bacterial eradication following treatment of exacerbations of chronic bronchitis. Thorax. 2003;58(8):680-685.

100. Banerjee D, Khair OA, Honeybourne D. Impact of sputum bacteria on airway inflammation and health status in clinical stable COPD. Eur Respir J. 2004;23(5):685-691.

101. Sethi S, Wrona C, Grant BJ, Murphy TF. Strain-specific immune response to Haemophilus influenzae in chronic obstructive pulmonary disease. Am J Respir Crit Care Med. 2004;169(4):448-453.

102. Murphy TF, Brauer AL, Schiffmacher AT, Sethi S. Persistent colonization by Haemophilus influenzae in chronic obstructive pulmonary disease. Am J Respir Crit Care Med. 2004;170(3):266-272.

103. Möller LV, Timens W, van der Bij W, et al. Haemophilus influenzae in lung explants of patients with end-stage pulmonary disease. Am J Respir Crit Care Med. 1998;157(3 Pt 1):950-956.

104. Murphy TF. Respiratory infections caused by non-typeable Haemophilus influenzae. Curr Opin Infect Dis. 2003;16(2):129-134.

105. Berenson CS, Garlipp MA, Grove LJ, Maloney J, Sethi S. Impaired phagocytosis of nontypeable Haemophilus influenzae by human alveolar macrophages in chronic obstructive pulmonary disease. J Infect Dis. 2006;194(10):1375-1384.

106. Leopold PL, O’Mahony MJ, Lian XJ, Tilley AE, Harvey BG, Crystal RG. Smoking is associated with shortened airway cilia. PLoS One. 2009;4(12):e8157.

107. Tamashiro E, Xiong G, Anselmo-Lima WT, Kreindler JL, Palmer JN, Cohen NA. Cigarette smoke exposure impairs respiratory epithelial ciliogenesis. Am J Rhinol Allergy. 2009;23(2):117-122.

108. Verra F, Escudier E, Lebargy F, Bernaudin JF, de Crémoux H, Bignon J. Ciliary abnormalities in bronchial epithelium of smokers, ex-smokers, and nonsmokers. Am J Respir Crit Care Med. 1995; 151(3 Pt 1):630-634.

109. Takeyama K, Jung B, Shim JJ, et al. Activation of epidermal growth factor receptors is responsible for mucin synthesis induced by cigarette smoke. Am J Physiol Lung Cell Mol Physiol. 2001; 280(1):L165-L172.

110. Cantin AM, Hanrahan JW, Bilodeau G, et al. Cystic fibrosis transmembrane conductance regulator function is suppressed in cigarette smokers. Am J Respir Crit Care Med. 2006;173(10):1139-1144.

111. Fahy JV, Dickey BF. Airway mucus function and dysfunction. $N$ Engl J Med. 2010;363(23):2233-2247.

112. Duim B, van Alphen L, Eijk P, Jansen HM, Dankert J. Antigenic drift of non-encapsulated Haemophilus influenzae major outer membrane protein $\mathrm{P} 2$ in patients with chronic bronchitis is caused by point mutations. Mol Microbiol. 1994;11(6):1181-1189.

113. Duim B, Vogel L, Puijk W, et al. Fine mapping of outer membrane protein $\mathrm{P} 2$ antigenic sites which vary during persistent infection by Haemophilus influenzae. Infect Immun. 1996;64(11):4673-4679.

114. Hiltke TJ, Schiffmacher AT, Dagonese AJ, Sethi S, Murphy TF. Horizontal transfer of the gene encoding outer membrane protein P2 of nontypeable Haemophilus influenzae, in a patient with chronic obstructive pulmonary disease. J Infect Dis. 2003;188(1):114-117.

115. Murphy TF, Kirkham C. Biofilm formation by nontypeable Haemophilus influenzae: strain variability, outer membrane antigen expression and role of pili. BMC Microbiol. 2002;2:7.
116. Eldika N, Sethi S. Role of nontypeable Haemophilus influenzae in exacerbations and progression of chronic obstructive pulmonary disease. Curr Opin Pulm Med. 2006;12(2):118-124.

117. Moghaddam SJ, Clement CG, de la Garza MM, et al. Haemophilus influenzae lysate induces aspects of the chronic obstructive pulmonary disease phenotype. Am J Respir Cell Mol Biol. 2008;38(6):629-638.

118. Lo B, Hansen S, Evans K, Heath JK, Wright JR. Alveolar epithelial type II cells induce $\mathrm{T}$ cell tolerance to specific antigen. $J$ Immunol. 2008;180(2):881-888.

119. Zissel G, Ernst M, Rabe K, et al. Human alveolar epithelial cells type II are capable of regulating T-cell activity. J Investig Med. 2000; 48(1):66-75.

120. Cunningham AC, Zhang JG, Moy JV, Ali S, Kirby JA. A comparison of the antigen-presenting capabilities of class II MHC-expressing human lung epithelial and endothelial cells. Immunology. 1997;91(3): $458-463$.

121. Gereke M, Jung S, Buer J, Bruder D. Alveolar type II epithelial cells present antigen to $\mathrm{CD} 4(+) \mathrm{T}$ cells and induce Foxp3(+) regulatory T cells. Am J Respir Crit Care Med. 2009;179(5):344-355.

122. Kheradmand F, Mattewal AS, Corry DB. At last, an immune organ we can call our own? Am J Respir Crit Care Med. 2009;179(7): $525-527$.

123. Evans SE, Scott BL, Clement CG, et al. Stimulated innate resistance of lung epithelium protects mice broadly against bacteria and fungi. Am J Respir Cell Mol Biol. 2010;42(1):40-50.

124. Ochoa CE, Mirabolfathinejad SG, Ruiz Venado A, et al. Interleukin 6 but not $\mathrm{T}$ helper 2 cytokines promotes lung carcinogenesis. Cancer Prev Res (Phila). 2011 Jan;4(1):51-64.

125. Jemal A, Siegel R, Ward E, Hao Y, Xu J, Thun MJ. Cancer statistics, 2009. CA Cancer J Clin. 2009;59(4):225-249.

126. Stellman SD, Takezaki T, Wang L, et al. Smoking and lung cancer risk in American and Japanese men: an international case-control study. Cancer Epidemiol Biomarkers Prev. 2001;10(11):1193-1199.

127. Shacter E, Weitzman SA. Chronic inflammation and cancer. Oncology (Williston Park). 2002;16(2):217-226, 229.

128. Young RP, Hopkins RJ, Hay BA, et al. Lung cancer susceptibility model based on age, family history and genetic variants. PLoS One. 2009;4(4):e5302.

129. Tockman MS, Anthonisen NR, Wright EC, Donithan MG. Airways obstruction and the risk for lung cancer. Ann Intern Med. 1987; 106(4):512-518.

130. Skillrud DM, Offord KP, Miller RD. Higher risk of lung cancer in chronic obstructive pulmonary disease. A prospective, matched, controlled study. Ann Intern Med. 1986;105(4):503-507.

131. De Torres JP, Bastarrika G, Wisnivesky JP, et al. Assessing the relationship between lung cancer risk and emphysema detected on low-dose CT of the chest. Chest. 2007;132(6):1932-1938.

132. Turner MC, Chen Y, Krewski D, Calle EE, Thun MJ. Chronic obstructive pulmonary disease is associated with lung cancer mortality in a prospective study of never smokers. Am J Respir Crit Care Med.2007; 176(3):285-290.

133. Houghton AM, Mouded M, Shapiro SD. Common origins of lung cancer and COPD. Nat Med. 2008;14(10):1023-1024.

134. Wang B, Lim DJ, Han J, Kim YS, Basbaum CB, Li JD. Novel cytoplasmic proteins of nontypeable Haemophilus influenzae up-regulate human MUC5AC mucin transcription via a positive p38 mitogen-activated protein kinase pathway and a negative phosphoinositide 3-kinase-Akt pathway. J Biol Chem. 2002;277(2):949-957.

135. Moghaddam SJ, Li H, Cho SN, et al. Promotion of lung carcinogenesis by chronic obstructive pulmonary disease-like airway inflammation in a K-ras-induced mouse model. Am J Respir Cell Mol Biol. 2009;40(4): 443-453.

136. Merrill RM, Isakson RT, Beck RE. The association between allergies and cancer: what is currently known? Ann Allergy Asthma Immunol. 2007;99(2):102-116. 
137. Ramanakumar AV, Parent ME, Menzies D, Siemiatycki J. Risk of lung cancer following nonmalignant respiratory conditions: evidence from two case-control studies in Montreal, Canada. Lung Cancer. 2006; 53(1):5-12.

138. Gorlova OY, Zhang Y, Schabath MB, et al. Never smokers and lung cancer risk: a case-control study of epidemiological factors. Int J Cancer. 2006;118(7):1798-1804.
139. Turner MC, Chen Y, Krewski D, Ghadirian P. An overview of the association between allergy and cancer. Int J Cancer. 2006;118(12) 3124-3132.

140. Littman AJ, Thornquist MD, White E, Jackson LA, Goodman GE, Vaughan TL. Prior lung disease and risk of lung cancer in a large prospective study. Cancer Causes Control. 2004;15(8):819-827.

International Journal of COPD

\section{Publish your work in this journal}

The International Journal of COPD is an international, peer-reviewed journal of therapeutics and pharmacology focusing on concise rapid reporting of clinical studies and reviews in COPD. Special focus is given to the pathophysiological processes underlying the disease, intervention programs, patient focused education, and self management protocols.

\section{Dovepress}

This journal is indexed on PubMed Central, MedLine and CAS. The manuscript management system is completely online and includes a very quick and fair peer-review system, which is all easy to use. Visit $\mathrm{http}: / /$ www.dovepress.com/testimonials.php to read real quotes from published authors.

Submit your manuscript here: http://www.dovepress.com/international-journal-of-copd-journal 